\title{
Clinicopathological evaluation of postmenopausal bleeding
}

\author{
Manjusha Agrawal, Monika K. Kotpalliwar*, Swadha Kotpalliwar
}

Department of Obstetrics and Gynecology, Jawaharlal Nehru Medical College, Sawangi (Meghe), Wardha, Maharashtra, India

Received: 07 October 2018

Accepted: 01 November 2018

\section{*Correspondence:}

Dr. Monika K. Kotpalliwar,

E-mail: monikakotpalliwar@gmail.com

Copyright: (C) the author(s), publisher and licensee Medip Academy. This is an open-access article distributed under the terms of the Creative Commons Attribution Non-Commercial License, which permits unrestricted non-commercial use, distribution, and reproduction in any medium, provided the original work is properly cited.

\section{ABSTRACT}

Background: Seventy percent of cases of postmenopausal bleeding have an innocent or harmless cause of bleeding but $30 \%$ of them are associated with malignancy. Hence it requires a thorough evaluation clinically and pathologically. As a considerable number of patients complaining of postmenopausal bleeding are reporting, the current study was undertaken to find out the incidence of the postmenopausal bleeding and the causes responsible for it.

Methods: A hospital based cross sectional study was performed on women with the history of post-menopausal bleeding. Patients with premature menopause whether surgical or natural (age <40 years), patients having bleeding from urethra or rectum and patients on hormone replacement therapy and anticoagulation therapy were excluded from the study. After the detailed history and a thorough examination, all the patients were subjected to USG. In cases, wherever required colposcopy, biopsy, laparotomy or hysterectomy was performed and were correlated histopathologically.

Results: Incidence of 11/1000 patients was found. The mean age of menopause was 46.99 years and mean duration was 7.20 years. Clinically the most common cause was Ca endometrium (26\%), whereas histopathologically atrophy $(34.61 \%)$ was the commonest cause. $61 \%$ had benign cause whereas $39 \%$ had malignant cause for post-menopausal bleeding.

Conclusions: From the study, it is revealed that the incidence of postmenopausal bleeding decreases with increase in the age of patient as well as with the increasing duration of the menopause. Scanty endometrium is associated normal histopathology of endometrium and hence patients of postmenopausal bleeding with endometrial thickness $>5 \mathrm{~mm}$ should be thoroughly investigated, treated and followed up meticulously.

Keywords: Ca endometrium, Endometrium thickness, Menopause

\section{INTRODUCTION}

Postmenopausal bleeding is a tornado in quiescent ocean of menopause as it brings turbulence and misery to the twilight of menopause. The term menopause is derived from the Greek words menos (month) and pause (to stop). Menopause is just not the cessation of menses, it is depletion of ovarian follicles leading to decrease in ovarian hormone. ${ }^{1}$ The average age of menopause is 51 years. ${ }^{2}$ WHO has defined postmenopausal bleeding as,
An episode of bleeding twelve months or more after the last menstrual period. $70 \%$ of cases of postmenopausal bleeding have an innocent or harmless cause of bleeding but $30 \%$ of them are associated with malignancy. Hence postmenopausal bleeding requires a thorough evaluation clinically and pathologically to exclude carcinoma as the cause and ensure a benign pathology.

Carcinoma of genital tract is one of the most important cause of postmenopausal bleeding. ${ }^{3}$ About $90 \%$ of 
patients with endometrial cancer present with postmenopausal bleeding, however $10 \%$ of patients with postmenopausal bleeding have endometrial cancer. ${ }^{4}$ Postmenopausal bleeding is an early presenting feature of endometrial cancer. $75 \%$ of the cases occur during postmenopausal period and nearly $90 \%$ of all endometrial carcinoma patients presents with abnormal vaginal bleeding as first symptom and are in early and curable stages. Trends in life expectancy show that people are living longer, and they have a right to live a long life in good health, rather than one of pain and misery due to malignancy. Thus, with the changing demographic pattern health care of post-menopausal women is one of the most important aspects in geriatric gynaecology. As a considerable number of patients complaining of postmenopausal bleeding are reporting in this centrally located tertiary care hospital, the current study was undertaken to study out the incidence of the postmenopausal bleeding and to evaluate the causes responsible for it both clinically and pathologically.

\section{METHODS}

A hospital based cross sectional study was performed on all women attending gynecology outpatient department with the history of post-menopausal bleeding.

\section{Exclusion criteria}

- Patients with premature menopause whether surgical or natural (age less than 40 years), patients having bleeding from urethra or rectum and patients on hormone replacement therapy and anticoagulation therapy.

The preliminary information about age, duration of bleeding, episode and amount of bleeding with interbleeding duration was noted in proforma. The other associated complaints as white discharge, urinary and bowel complaints were interrogated, a word of weight and/or appetite loss was not missed. A detailed menstrual history was recorded including age of menarche, age and duration of menopause and how was it attained and also about the past menstrual cycle.

The age of marriage, first child birth, parity and last child birth was recorded, significant past medical history was also noted. Use of oral contraceptives, intrauterine device, hormones if taken duration was asked on leading basis, previous history of curettage if done histopathology report, details of treatment taken, and history of radiotherapy was also noted. After completing the detailed history, a thorough general examination was done including weight, obvious obesity, pallor, vitals, blood pressure, lymphadenopathy, edema feet and breast examination. A systemic examination was done including respiratory system, cardiovascular system, abdomen for liver and spleen or any lump. Local examination was done gently, carefully and thoroughly in lithotomy position with empty bladder, to inspect vulva for atrophic changes, local ulcer or infection, urethral caruncle and presence of prolapse.

Per speculum examination was done for atrophic changes in vagina, vaginitis trauma or presence of growth. Cervix was visualized for hypertrophy, erosion, inflammation, growth, decubitus ulcer or polyp. At this time, cervical cytology was taken with Ayres Wooden spatula from the squamocolumnar junction. Scrapes from endocervix were taken with the help of endobrush, if there was presence of growth biopsy was taken. Bimanual examination was done to note the size of uterus, mobility, anteversion, retroversion, consistency and adnexa for mass. It was followed by rectal examination.

Relevant blood investigation including haemoglobin percentage, peripheral smear, bleeding time, clotting time, blood sugar fasting, post meal and urine examination for albumin and sugar was done. Ultrasonography of pelvis was carried out to measure the endometrial thickness and to rule out any other pathological conditions. If there was suspicious area over cervix, colposcopy was done and colposcopically directed biopsy was performed. Except, cervical cancer and prolapsed with decubitus ulcer all patients were subjected to fractional curettage after taking informed consent.

In case, where laparotomy/hysterectomy was performed details of gross examination i.e. uterine size, cut surface for submucous fibroid, endocervical growth, endometrial cancer and its gross myometrial invasion or any other cause for bleeding and histopathological findings were noted in proforma and observations were made.

\section{RESULTS}

A hospital based cross sectional study was carried out in 100 patients of postmenopausal bleeding attending Gynaecology outpatient department of Acharya Vinoba Bhave Rural Hospital to study the incidence of postmenopausal bleeding and to evaluate the various causes of postmenopausal bleeding clinically and pathologically.

Table 1: Distribution of study subjects according to age $(n=100)$.

\begin{tabular}{|lll|}
\hline Age (years) & No. of study subjects & Percentage \\
\hline $41-45$ & 7 & 7 \\
\hline $46-50$ & 29 & 29 \\
\hline $51-55$ & 27 & 27 \\
\hline $56-60$ & 21 & 21 \\
\hline $61-65$ & 11 & 11 \\
\hline $66-70$ & 5 & 5 \\
\hline Total & 100 & 100 \\
\hline fc2-value $=32.36$, df $=5$, Significant & \\
\hline
\end{tabular}

Total patients attending the Gynaecology out patient's department during the study period were 9000 cases 
(new) giving an incidence of $11 / 1000$ patients. As described in Table 1, the age range of study subjects was 41-70 years and mean age was 54.51 years. Maximum i.e. $29 \%$ were between $46-50$ years. As mentioned in table 2, range of age of menopause was between $40-56$ years.

Table 2: Distribution of study subjects according to age of menopause $(n=100)$.

\begin{tabular}{|lll|}
\hline $\begin{array}{l}\text { Age of menopause } \\
\text { (years) }\end{array}$ & $\begin{array}{l}\text { No. of study } \\
\text { subjects }\end{array}$ & Percentage \\
\hline $40-45$ & 31 & 31 \\
\hline $46-50$ & 56 & 56 \\
\hline $51-55$ & 12 & 12 \\
\hline $56-60$ & 1 & 1 \\
\hline Total & 100 & 100 \\
\hline
\end{tabular}

Mean age of menopause was 46.99 years. Maximum i.e. $56 \%$ were between $46-50$ years. As per table 3, mean duration of menopause was 7.20 years. Maximum i.e. $37 \%$ had duration of menopause between 1-4 years.

Table 3: Distribution of study subjects according to duration of menopause $(n=100)$.

\begin{tabular}{|lll|}
\hline Years & No. of study subjects & Percentage \\
\hline $1-4$ & 37 & 37 \\
\hline $5-8$ & 25 & 25 \\
\hline $9-12$ & 18 & 18 \\
\hline $13-16$ & 16 & 16 \\
\hline $17-20$ & 3 & 3 \\
\hline$>20$ & 1 & 1 \\
\hline Total & 100 & 100 \\
\hline
\end{tabular}

$\mathrm{k} 2$-value $=55.04, \mathrm{df}=5$, Significant

According to Figure 1, the range of parity was 0 to 8 . Mean parity was 3.62. All cases of cancer cervix were having parity more than 3 and in carcinoma endometrium $50 \%$ cases were nulliparous and $50 \%$ were 3 para. Mean age of menarche was 13.75 years. Menstrual pattern before menopause was abnormal in $12 \%$ and in rest it was normal.

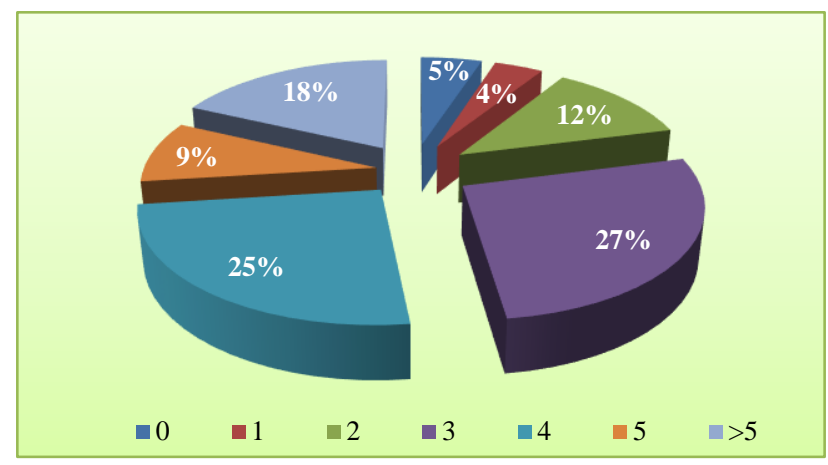

Figure 1: Distribution of subjects according to parity $(\mathbf{n}=\mathbf{1 0 0})$.
As stated in Figure 2, clinically $26 \%$ had carcinoma endometrium, $25 \%$ had cervical malignancy, $17 \%$ had prolapse with decubitus ulcer, $9 \%$ had fibroid uterus, atypical hyperplasia 7.69\%, 7.69\% adenocarcinoma, cervical mucous polyp $3 \%$ and ovarian tumour in $3 \%$. In $15 \%$ clinically cause could not be detected.

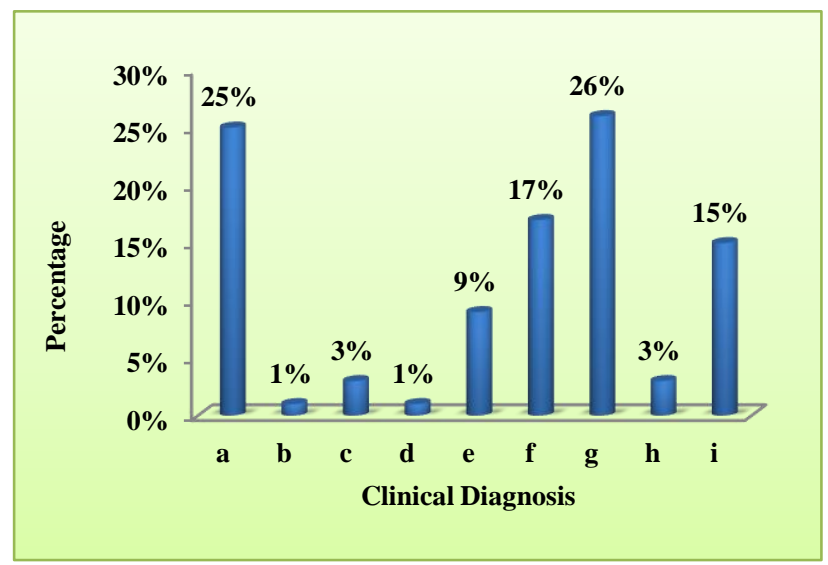

a - Ca cervix, b - Cervicitis, c - Cervical mucous polyp, d - Fibroid polyp, e - Fibroid uterus, f - Prolapse with decubitus ulcer, g - Ca endometrium, $\mathrm{h}$ - Ovarian tumor, i - Clinically cause not detected

Figure 2: Distribution of study subjects according to clinical diagnosis $(n=100)$

According to Figure 3, Table 4 and 5, histopathologically atrophy was the commonest i.e. $34.61 \%$ followed by proliferative $25.64 \%$, secretory $12.82 \%$, atypical hyperplasia $7.69 \%, 7.69 \%$ adenocarcinoma, simple hyperplasia $6.41 \%$, endometrial polyp $2.57 \%$ and $2.57 \%$ had insufficient sample. Carcinoma endometrium was over diagnosed clinically.

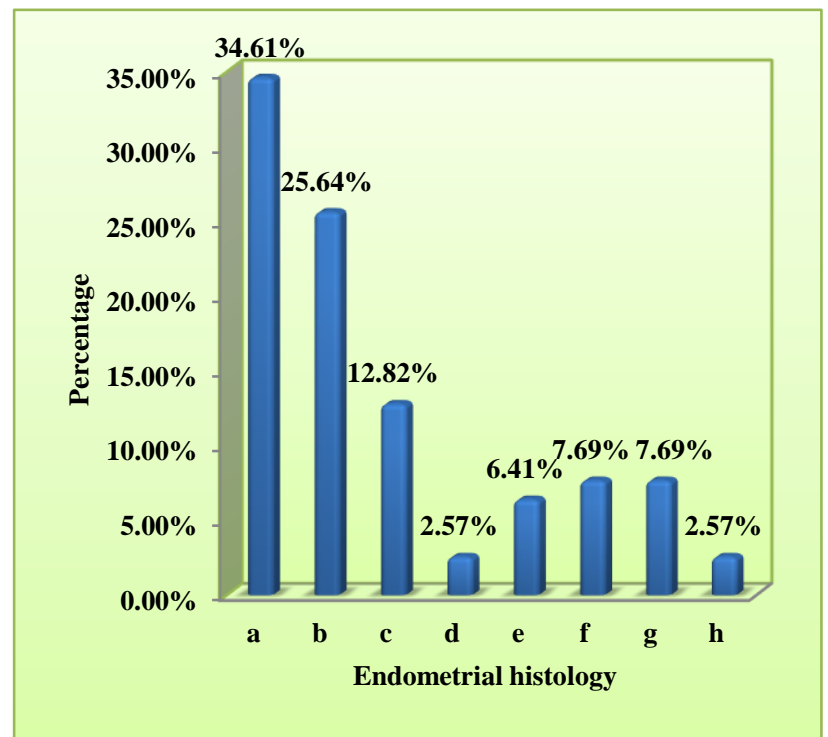

a-Atrophy, b-Proliferative, c-Secretory, d-Polyp, e-Simple Hypoplasia, f-Atypical Hyperplasia, g-Adenocarcinoma, h-Insufficient sample

Figure 3: Distribution of subjects according to histopathological diagnosis $(n=78)$. 
Table 4: Histopathological diagnosis of 26 cases clinically diagnosed as carcinoma endometrium.

\begin{tabular}{|lll|}
\hline Endometrium & No. of cases & Percentage \\
\hline Proliferative & 2 & 7.69 \\
\hline Secretory & 2 & 7.69 \\
\hline Polyp & 2 & 7.69 \\
\hline Simple hyperplasia & 1 & 3.85 \\
\hline Atypical hyperplasia & 1 & 3.85 \\
\hline Adenocarcinoma & 6 & 23.08 \\
\hline Fibroid uterus & 5 & 19.23 \\
\hline Adenomyosis & 7 & 26.92 \\
\hline Total & 26 & 100.00 \\
\hline
\end{tabular}

k2-value $=12.15, \mathrm{df}=7$, Not Significant

As mentioned in Table 6, range of endometrial thickness was $2-28 \mathrm{~mm}$. $44.87 \%$ had thickness $<5 \mathrm{~mm}$ and $55.13 \%$ had more than $5 \mathrm{~mm}$. On fractional curettage endometrium obtained was moderate in $47.54 \%$, bulky in $27.87 \%$ and scanty in $24.59 \%$.

Table 5: Distribution of 15 cases according to histopathological finding in whom clinically cause could not be detected.

\begin{tabular}{|lll|}
\hline Endometrium & Cases & Percentage \\
\hline Proliferative & 1 & 6.67 \\
\hline Secretory & 1 & 6.67 \\
\hline Cystic hyperplasia & 1 & 6.67 \\
\hline Atypical hyperplasia & 3 & 20 \\
\hline Atrophy & 9 & 60 \\
\hline Total & 15 & 100 \\
\hline k2-value $=16.00, \mathrm{df}=4$, Not Significant & \\
\hline
\end{tabular}

As described in Table 7 and 8, when fractional curettage findings were related with transvaginal sonography and histopathological findings, in all cases of scanty endometrium, endometrial thickness was $<5 \mathrm{~mm}$ and histopathology was normal, whereas all cases of bulky endometrium had endometrial thickness $>5 \mathrm{~mm}$ with abnormal histology in $88.23 \%$ of cases. Out of 100 cases the cause of postmenopausal bleeding was benign in $61 \%$ and malignant in $39 \%$.

Table 6: Distribution of study subjects according to endometrial thickness $(n=78)$.

\begin{tabular}{lll}
$\begin{array}{l}\text { Endometrial } \\
\text { thickness } m m\end{array}$ & $\begin{array}{l}\text { No. of study } \\
\text { subjects }\end{array}$ & Percentage \\
\hline$<5 \mathrm{~mm}$ & 35 & 44.87 \\
\hline $6-10$ & 19 & 24.36 \\
\hline $11-15$ & 10 & 12.83 \\
\hline $16-20$ & 11 & 14.10 \\
\hline $21-25$ & 2 & 2.56 \\
\hline$>25$ & 1 & 1.28 \\
\hline
\end{tabular}

As per table 9, the benign causes for postmenopausal bleeding were prolapse with decubitus ulcer $27.87 \%$, dysfunctional uterine bleeding $27.87 \%$, fibroid $21.31 \%$, adenomyosis $11.48 \%$, cervical mucous polyp $4.92 \%$, ovarian tumour $1.64 \%$, fibroid polyp $3.28 \%$ and cervicitis with senile vaginitis $1.64 \%$.

Table 7: Relation of endometrium on fractional curettage with transvaginal sonography and histopathological findings $(n=61)$.

\begin{tabular}{|c|c|c|c|c|}
\hline \multirow[t]{2}{*}{$\begin{array}{l}\text { Endometrium } \\
\text { on curettage }\end{array}$} & \multicolumn{2}{|c|}{$\begin{array}{l}\text { Endometrial } \\
\text { thickness on } \\
\text { transvaginal } \\
\text { sonography }\end{array}$} & \multicolumn{2}{|c|}{ Histopathology } \\
\hline & $<5 \mathrm{~mm}$ & $>5 \mathrm{~mm}$ & Normal & Abnormal \\
\hline Scanty $n=15$ & 15 & & 15 & \\
\hline Moderate $n=29$ & 6 & 23 & 24 & 5 \\
\hline Bulky n=17 & & 17 & 2 & 15 \\
\hline
\end{tabular}

Table 8: Endometrial thickness with cut-off point of 5 $\mathrm{mm}$ and its relation to histological diagnosis $(n=78)$.

\begin{tabular}{|lllll|}
\hline \multirow{2}{*}{ Endometrial diagnosis } & \multicolumn{4}{l}{ Endometrial thickness } \\
& $<5 \mathrm{~mm}$ & $>5 \mathrm{~mm}$ \\
\hline Insufficient sample & 2 & 2.57 & & \\
\hline Atrophy & 27 & 34.61 & & \\
\hline Proliferative & 06 & 7.69 & 14 & 17.95 \\
\hline Secretory & & & 10 & 12,82 \\
\hline Polyp & & & 2 & 2.57 \\
\hline Simple hyperplasia & & & 5 & 6.41 \\
\hline Atypical endometrium & & & 6 & 7.69 \\
\hline Adenocarcinoma & & & 6 & 7.69 \\
\hline & 35 & 44.87 & 43 & 55.13 \\
\hline
\end{tabular}

Table 9: Distribution of study subjects according to benign causes of post-menopausal bleeding $(n=61)$.

\begin{tabular}{|lll|}
\hline Causes & $\begin{array}{l}\text { No. of } \\
\text { study } \\
\text { subjects }\end{array}$ & Percentage \\
\hline Prolapsed with decubitus ulcer & 17 & 27.87 \\
\hline DUB & 17 & 27.87 \\
\hline Fibroid uterus & 13 & 21.31 \\
\hline Adenomyosis & 7 & 11.48 \\
\hline Ovarian tumor & 1 & 1.64 \\
\hline Fibroid polyp & 2 & 3.28 \\
\hline Cervicitis with senile vaginitis & 1 & 1.64 \\
\hline Cervical mucous polyp & 3 & 4.92 \\
\hline Total & 61 & 100 \\
\hline
\end{tabular}

Table 10: Distribution of study subjects according to malignant causes of post-menopausal bleeding $(n=39)$.

\begin{tabular}{|lll|}
\hline Causes & $\begin{array}{l}\text { No. Of study } \\
\text { subjects }\end{array}$ & Percentage \\
\hline Carcinoma cervix & 25 & 64.10 \\
\hline Atypical endometrium & 6 & 15.38 \\
\hline $\begin{array}{l}\text { Adenocarcinoma } \\
\text { endometrium }\end{array}$ & 6 & 15.38 \\
\hline Ovarian cancer & 2 & 5.13 \\
\hline Total & 39 & 100 \\
\hline
\end{tabular}


As mentioned in Table 10, the malignant causes for postmenopausal bleeding were carcinoma cervix commonest $64.10 \%$, atypical endometrium $15.38 \%$, adenocarcinoma $15.38 \%$, and ovarian carcinoma $5.13 \%$. The commonest site of origin of bleeding was uterus in $51 \%$ of cases followed by cervix $46 \%$ and ovary $3 \%$. High risk factors like diabetes mellitus, hypertension and obesity were associated more with malignant condition as compared with benign condition.

As stated in Table 11, in malignant condition, carcinoma endometrium was more associated with these risk factors like diabetes mellitus and hypertension (33.33\%) as compared to carcinoma cervix $(20 \%)$.

Table 11: Distribution of study subjects according to risk factors in benign and malignant conditions.

\begin{tabular}{|lllll|}
\hline Risk factors & Benign & Cancer cervix & Cancer endometrium & Cancer ovary \\
\hline Hypertension & $28(45.16)$ & $10(40)$ & $1(16.67)$ & $1(50)$ \\
\hline Diabetes & & $5(20)$ & $1(16.67)$ & \\
\hline Hypertension and diabetes & $5(8.06)$ & $5(20)$ & $2(33.33)$ & $1(50)$ \\
\hline $\begin{array}{l}\text { Obesity } \\
\text { No risk factor }\end{array}$ & $10(16.13)$ & & & 4 \\
\hline Mean parity & $18(30.75)$ & $10(40)$ & 3 & $2(100)$ \\
\hline Total & 3.75 & 4.80 & $6(100)$ & \\
\hline
\end{tabular}

k2-value $=7.90, p$-value $=0.54$, Not Significant

Table 12: Distribution of study subjects according to management.

\begin{tabular}{|c|c|c|c|c|c|c|}
\hline Diagnosis & Operative & $\begin{array}{l}\text { Radiotherapy } \\
\text { (referred) }\end{array}$ & Chemotherapy & Follow up & Lost to follow up & Total \\
\hline Prolapse with decubitus ulcer & 17 & & & & & 17 \\
\hline DUB & 3 & & & 10 & 4 & 17 \\
\hline Fibroid uterus & 13 & & & & & 13 \\
\hline Adenomyosis & 7 & & & & & 7 \\
\hline Ovarian tumor & 03 & & 2(post op) & & & 3 \\
\hline Fibroid polyp & 1 & & & & 1 & 2 \\
\hline Cervical mucous polyp & & & & 3 & & 3 \\
\hline Cervicitis & 1 & & & & & 1 \\
\hline Cancer cervix & 3 & 22 & & & & 25 \\
\hline Atypical endometrium & 06 & & & & & 06 \\
\hline Cancer endometrium & 06 & 01 (post op) & & & & 06 \\
\hline Total & 60 & 23 & 2 & 13 & 5 & 100 \\
\hline
\end{tabular}

As per Table 12, out of 100 patients, 5 patients were lost to follow up, 60 were managed by different operative procedures, 23 by radiotherapy, 2 by chemotherapy, in 13 cases minor operative procedures were done and followed up.

\section{DISCUSSION}

Postmenopausal bleeding is one of the most important geriatric health problems as it alarms about genital malignancy, although $90 \%$ cases have benign cause for postmenopausal bleeding. Present study is undertaken to find out the different causes of post-menopausal bleeding and its incidence. Incidence of postmenopausal bleeding in present study was 11 per 1000 (100/9000) new cases. In the present study the age range was 41-70 years. It was observed that maximum number of cases i.e. $29 \%$ were in the age group of 46-50 years and minimum in 66-70 years i.e. $5 \%$. Mean age was 54.51 years. It was also observed that as the age of study subjects goes on increasing the incidence of postmenopausal bleeding goes on decreasing indicating inverse relationship between age and age of post-menopausal bleeding (Table 1). This finding was similar to the study conducted by Lidor et al which stated mean age of menopause as 56 years. ${ }^{5}$ Gredmark $\mathrm{T}$ et al in his 18 months prospective study revealed that the number of cases of postmenopausal bleeding decline with increasing age. ${ }^{6}$ Age range of study subjects was 50-80 years and maximum cases were less than 50 years age group i.e. $2.18 \%$. In present study maximum number of study subjects $37 \%$ had duration of menopause between 1-4 years, followed by $25 \%$ between 5-8 years, $18 \%$ between $9-12$ years, $16 \%$ between $13-16$ years and $3 \%$ between 17-20 years and only one case i.e. $01 \%$ had duration more than 20 years. Mean duration of menopause was 7.20 years (Table 2). 
Study revealed that as the duration of menopause increases the chances of postmenopausal bleeding decreases. Agrawal $\mathrm{L}$ et al in their study revealed that maximum percentage of cases i.e. $55.33 \%$ had duration of menopause between $1-5$ years. ${ }^{7}$ When the distribution of malignant cases according to parity was studied it was observed that, of the 25 cases of cancer cervix, 7 cases were 3 para, 5 cases 4 para, 3 cases para 5, $10(40 \%)$ cases more than 5 para. In cancer endometrium, out of 6 cases, it was observed that 3 cases were nulliparous, and 3 cases were 3 para. In atypical endometrium which is precancerous stage, out of the 6 cases, 3 cases were 3 para and 1 case was 2 para, 1 more than 5 para while one nullipara. Agrawal L et al observed that parity ranged from $0-8$ and maximum cases i.e. $29.33 \%$ were 3 para. $^{7}$ It was observed that maximum number of subjects i.e. $62 \%$ had scanty cycles and $12 \%$ had menorrhagia. $50 \%$ of cancer endometrium patients had menorrhagia as compared to only $12 \%$ of benign conditions. Hence it is suggested that all patients with abnormal menopause i.e. menorrhagia should be investigated and thoroughly followed up as 50\% risk of cancer endometrium was noted in the present study. According to Dewhurst, in $50 \%$ of perimenopausal women with dysfunctional uterine bleeding where cycles were acyclic and were associated with endometrial hyperplasia.

In the present study, Carcinoma endometrium was the most common clinical presentation i.e. in 26 (26\%) cases, carcinoma cervix was the second most common in 25
(25\%) cases, followed by $17(17 \%)$ cases of prolapse with decubitus ulcer, $9(\%)$ cases were diagnosed as fibroid uterus. Other clinical diagnosis were cervical mucous polyp $3(3 \%)$ cases, ovarian tumour $3(3 \%)$ cases, cervicitis $1(1 \%)$ case. In $15(15 \%)$ cases clinically cause could not be detected (Figure 2). Of the 26 cases clinically diagnosed as cancer endometrium, after histopathological examination of endometrium it was observed that in $6(23.08 \%)$ cases only cancer endometrium was detected. $7(26.92 \%)$ cases had adenomyosis, $5(19.23 \%)$ cases had fibroid uterus, 2 $(7.69 \%)$ cases each had proliferative, secretory and endometrial polyp. One $(3.85 \%)$ case had simple hyperplasia (Table 4). From this it is observed that there is always an over diagnosis of endometrial cancer clinically and hence it necessitates thorough investigation and endometrial histopathology. In 25 cases of carcinoma cervix, diagnosis was confirmed by biopsy.

Among 15 cases in whom cause could not be detected clinically histopathology of endometrium showed that maximum cases i.e. $9(60 \%)$ cases had atrophy of endometrium, $3(20 \%)$ cases had atypical endometrium in rest of $3(20 \%)$ cases each case of proliferative, secretory and cystic hyperplasia (Table 5). In the present study, 22 cases with obvious growth over cervix were refrained from fractional curettage and transvaginal sonography. In remaining 78 cases endometrial thickness was measured by transvaginal sonography and then these cases were subjected to fractional curettage.

Table 13: Histopathological findings of various studies and the present study.

\begin{tabular}{|c|c|c|c|c|c|c|c|c|}
\hline & $\begin{array}{l}\text { Lidor A } \\
\text { et } \mathrm{al}^{5} \\
(\mathrm{n}=226)\end{array}$ & $\begin{array}{l}\text { Do rum A } \\
\text { et } \mathbf{a l}^{8} \\
(n=100)\end{array}$ & $\begin{array}{l}\text { Gredmark } \\
\text { T et } \mathrm{al}^{6} \\
(\mathrm{n}=\mathbf{4 5 7})\end{array}$ & $\begin{array}{l}\text { Haller } \\
\text { H et al } \\
(n=81)\end{array}$ & 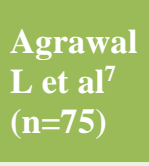 & $\begin{array}{l}\text { Ind } T^{9} \\
(n=4592)\end{array}$ & $\begin{array}{l}\text { Reddi } \\
\text { RP et } \\
\text { al }^{11} \\
(n=50)\end{array}$ & $\begin{array}{l}\text { Present } \\
\text { study } \\
(n=100)\end{array}$ \\
\hline Atrophy & $46 \%$ & $50 \%$ & $49.90 \%$ & $14.8 \%$ & $30.66 \%$ & $44.74 \%$ & - & $34.61 \%$ \\
\hline Proliferative & $14 \%$ & $12 \%$ & $4.2 \%$ & $23.93 \%$ & $10.66 \%$ & $8.8 \%$ & $30 \%$ & $25.64 \%$ \\
\hline Secretory & - & - & $1.3 \%$ & - & $8.0 \%$ & $1 \%$ & $2 \%$ & $12.82 \%$ \\
\hline Polyp & $8 \%$ & $7 \%$ & $9.2 \%$ & $19.75 \%$ & $5.33 \%$ & $13.1 \%$ & $8 \%$ & $2.57 \%$ \\
\hline $\begin{array}{l}\text { Simple } \\
\text { hyperplasia }\end{array}$ & \multirow{2}{*}{$115 \%$} & $3 \%$ & $2.6 \%$ & \multirow{2}{*}{$19.75 \%$} & \multirow{2}{*}{$26.66 \%$} & $8.6 \%$ & - & $6.41 \%$ \\
\hline $\begin{array}{l}\text { Atypical } \\
\text { hyperplasia }\end{array}$ & & - & $1.8 \%$ & & & $1.9 \%$ & $8 \%$ & $7.69 \%$ \\
\hline $\begin{array}{l}\text { Adeno- } \\
\text { carcinoma }\end{array}$ & $7 \%$ & $15 \%$ & $8.1 \%$ & $19.75 \%$ & $4 \%$ & $11 \%$ & $12 \%$ & $7.69 \%$ \\
\hline $\begin{array}{l}\text { Insufficient } \\
\text { sample }\end{array}$ & $10 \%$ & $10 \%$ & $14.2 \%$ & - & - & - & $22 \%$ & $2.57 \%$ \\
\hline
\end{tabular}

The type of endometrium obtained in fractional curettage was noted. In maximum, $29(47.54 \%)$ cases endometrium was moderate. In 15 (24.59\%) cases endometrium was scanty; in $17(27.87 \%)$ cases endometrium was bulky. In two cases endometrium could not be obtained. Histopathological findings in these 78 patients were as follows: Maximum percentage of cases had atrophy i.e. $27(34.61 \%)$ followed by proliferation $20(25.64 \%)$. secretory $10(12.82 \%)$, atypical hyperplasia $6(7.69 \%)$, adenocarcinoma $6(7.69 \%)$, simple hyperplasia 5 (6.41\%), endometrial polyp $2(2.57 \%)$. Insufficient sample was obtained in $2(2.57 \%)$ (Table 13$)$. 
It is observed that in patients with postmenopausal bleeding the commonest histopathological diagnosis of endometrium was endometrial atrophy the incidence of atrophy was found to be $46 \%$ by Lidor A et al, $49.90 \%$ by Gredmark T et al, $50 \%$ by Dorum A et al, $44.74 \%$ by Ind T, $30.66 \%$ by Agrawal Let al. ${ }^{5-9}$ Haller $\mathrm{H}$ et al and Reddi Rani $\mathrm{P}$ et al in their study observed commonest finding as proliferative endometrium i.e. $23.93 \%$ and $30 \%$ respectively. ${ }^{10,11}$ In the present study, proliferative endometrium was the next common observation i.e. $25.64 \%$. Secretory endometrium was observed in $12.82 \%$ in the present study while a very low incidence was reported by other authors i.e. $1.3 \%$ by Gredmark $\mathrm{T}$ et al, $1 \%$ by Ind T, $2 \%$ by Reddy Rani P et al, only Agrawal L et al observed $8 \%$ as secretory endometrium. ${ }^{6,9,11,7}$ The higher incidence in the present study may be due to fluctuating levels of progesterone from follicular remnants as decline of ovarian function in postmenopausal women is a gradual process. Endometrial polyp was observed in $8 \%$ by Lidor A et al, $9.2 \%$ by Gredmark $\mathrm{T}$ et al, $13.75 \%$ by Haller $\mathrm{H}$ et al, $7 \%$ by Dorum A et al, $13.1 \%$ by Ind T, $8 \%$ by Reddy Rani P et al, $5.33 \%$ by Agrawal L et al, while a low incidence was observed in the present study i.e. $2.57 \% .^{5-11}$

Simple hyperplasia in the present study was observed in $6.41 \%$ which is almost comparable with finding of Ind T of $8.6 \%$ while Dorum $\mathrm{A}$ et al and Gredmark $\mathrm{T}$ et al observed low incidence of 3 and $2.6 \%$ respectively. ${ }^{8,6}$ In the present study atypical endometrium a precancerous condition was observed in $7.69 \%$ which is comparable to Reddi Rani P et al i.e. $8 \% .{ }^{11}$ While others observed a low prevalence of $1.8 \%$ by Gredmark $\mathrm{T}$ et al, $1.9 \%$ by Ind T. 6 ,9 Endometrial carcinoma the most important and threatened cause of postmenopausal bleeding was found in $7.69 \%$ in the present study while $7 \%$ by Lidor A et al, $8.1 \%$ by Gredmark $\mathrm{T}$ et al and $4 \%$ by Agrawal Letal. ${ }^{5-7}$ A slightly higher incidence was observed by other authors i.e. $11 \%$ by Ind T, $12 \%$ by Reddi Rani P et al, $15 \%$ by Dorum A et al, $19.75 \%$ by Haller $\mathrm{H}$ et al. ${ }^{8-10}$ Higher incidence of endometrial malignancy i.e. $15 \%$ in Dorum A et al may be attributed to higher age range of his study subjects i.e. 56-89 years compared to 50-70 years in the present study. ${ }^{8}$

The range of endometrial thickness in the present study was between $2 \mathrm{~mm}$ and $28 \mathrm{~mm}$. In 22 cases of Carcinoma cervix endometrial thickness could not be studied from Table 8 it was observed that endometrial atrophy had endometrial thickness of less or equal to $5 \mathrm{~mm}$ and in pathological condition of endometrium the endometrial thickness was more than $6 \mathrm{~mm}$. With the cutoff point of 5 $\mathrm{mm}$, its relation with histological diagnosis revealed that $44.87 \%$ cases had endometrial thickness $<5 \mathrm{~mm}$, which included all cases of atrophy, insufficient sample and 6 cases of proliferative endometrium. $55.13 \%$ of cases had endometrial thickness more than $5 \mathrm{~mm}$ which included abnormal histological findings such as polyp, simple and atypical hyperplasia and adenocarcinoma. Various authors have studied the endometrial thickness with cutoff point of $5 \mathrm{~mm}$ and its co-relation with endometrial histopathology. Nasri MN et al in his study, $63 \%$ of the endometrium was atrophic and ultrasound endometrial thickness was $5 \mathrm{~mm}$ or less. ${ }^{12}$ In $31 \%$ patients endometrial histology was abnormal and endometrial thickness was more than $5 \mathrm{~mm}$. Karlsson B et al in his multicentre study concluded that, the risk of finding pathologic endometrium at curettage when the endometrium is $<4 \mathrm{~mm}$ as measured by transvaginal sonography is $5.5 \% .^{13}$ Thus, in women with postmenopausal bleeding and an endometrium $<4 \mathrm{~mm}$ it would seem justified to refrain from curettage. In the present study, when the relation of findings of fractional curettage, transvaginal sonography and histopathological findings were studied it was observed that in all 13 cases of scanty endometrium, endometrial thickness was $<5$ $\mathrm{mm}$ and histopathology was normal. Whereas, in all 17 cases of bulky endometrium had endometrial thickness $>5 \mathrm{~mm}$ and abnormal histology in $94.12 \%$ of cases (Table 7).

From this it can be concluded that whenever a patient of post-menopausal bleeding comes, transvaginal sonography, a noninvasive technique should be done to know the endometrial thickness and if it is $<5 \mathrm{~mm}$ supposing the normal histopathology patients may be followed up and one can refrain from invasive procedure i.e., fractional curettage. In the present study, after obtaining the histopathology of endometrium the cases were divided into benign and malignant cause of postmenopausal bleeding (Table 7) and it was observed that $60.78 \%$ were having benign cause and $39.22 \%$ were having malignant cause for postmenopausal bleeding. From the study, it is revealed that the incidence of postmenopausal bleeding decreases as the age of the patient increases. Similarly, the incidence of postmenopausal bleeding decreases as the duration of menopause increases. Age of menarche has no relation with postmenopausal bleeding. Post-menopausal bleeding was most common in multiparous women. The commonest cause for postmenopausal bleeding was atrophy and carcinoma cervix. Scanty endometrium was associated with endomtetrial thickness $<5$ and normal histopathology of endometrium and hence patients of postmenopausal bleeding with endometrial thickness $>5$ $\mathrm{mm}$ should be thoroughly investigated, treated and followed up meticulously.

Brewer $\mathrm{J} 1$ et al observed that benign lesion were in $36.9 \%$, malignant lesion in $26.6 \%$ and in $36.5 \%$ cause was not demonstrated. ${ }^{14}$ In the present study among the benign causes of postmenopausal bleeding $27.87 \%$ were having prolapse with decubitus ulcer and $27.87 \%$ were having dysfunctional uterine bleeding. The next common cause was fibroid uterus $21.31 \%$ followed by adenomyosis $11.48 \%$, cervical mucous polyp $4.92 \%$, ovarian tumour $1.64 \%$, fibroid polyp $3.28 \%$, cervicitis with senile vaginitis $1.64 \%$ (Table 9). In the present study among the malignant causes of postmenopausal bleeding carcinoma cervix was the most common cause 
i.e. in $64.10 \%$, followed by atypical endometrium in $15.38 \%$, adenocarcinoma in $15.38 \%$, functioning ovarian tumour, granulosa cell tumour in $5.13 \%$ (Table 10).

Brewer JI et al observed benign causes of postmenopausal bleeding as polyp $45.12 \%$, endometrial hyperplasia $13.41 \%$, fibroid $12.19 \%$, endocervicitis $9.75 \%$, papillary cystadenoma $2.44 \%$, follicular cyst $1.22 \%$, vaginitis $1.22 \%$ vaginal ulcer $6.09 \%$, vaginal endometrosis $1.22 \%$, urethral caruncle $1.22 \%$, vulval ulcer $1.22 \%$, resumption of menses $2.43 \%$. Among malignant causes, cancer endometrium was in $45.76 \%$, mixed mesenchymal tumour $3.70 \%$, sarcoma fibroid $3.70 \%$, cancer cervix $40.67 \%$, cancer ovary $6.78 \%$, cancer tube $3.70 \%$, cancer vulva $3.70 \% .^{7}$ When the risk factors were studied in benign and malignant conditions (Table 11) it showed that hypertension and diabetes mellitus were more with cancer endometrium i.e. $33.33 \%$ while $20 \%$ in cancer cervix and only $8.06 \%$ in benign conditions. Obesity was present in $33.33 \%$ in cancer endometrium, none in cancer cervix and $16.13 \%$ in benign condition of postmenopausal bleeding.

Cancer cervix was associated with higher mean parity i.e. 4.80 as compared to cancer endometrium i.e. 3.00. In study of Lidor A et al the common disease associated with post-menopausal bleeding encountered were hypertension, diabetes mellitus, obesity and their combinations in $28 \%$ of the patients and $40 \%$ in the carcinoma group. ${ }^{5}$ Ind $\mathrm{T}$ in his meta-analysis noted that endometrial malignancy was associated with obesity in $33 \%$, diabetes in $31 \%$ and hypertension in $30.7 \% .{ }^{9}$ Out of 100 cases of post-menopausal bleeding 9 cases were treated with different operative procedures. In 1 case of carcinoma endometrium adjuvant radiotherapy was given, 22 cases of carcinoma cervix were treated with radiotherapy. 10 cases of dysfunctional uterine bleeding which had atrophic endometrium and thickness was less than $5 \mathrm{~mm}$ were followed up. 3 cases of mucous polyp of cervix, avulsion of polyp was done, and endometrium showed atrophy was followed up. One case of cervicitis was followed up and 5 cases were lost to follow up (Table 12).

\section{ACKNOWLEDGMENTS}

Authors would like to thank Department of Radiodiagnosis and department of Pathology, Jawaharlal Nehru Medical College.

\section{Funding: No funding sources}

Conflict of interest: None declared

Ethical approval: The study was approved by the Institutional Ethics Committee

\section{REFERENCES}

1. Narendra Malhotra Jeffcoates principles of Gynaecology Jaypee Brothers Medical Publishers $7^{\text {th }}$ ed:862.

2. Khadija, Asaf $\mathrm{H}$, samina Hamid. Causes of postmenopausal bleeding. Pak J Obstet Gynaecol 10(3):22-6.

3. Tahir SM Professional Med J Sep. 2008;15(3):328-4.

4. Wong SF, Luk KL, Wing Ayk, Tang LCH. Finding in the women with post-menopausal bleeding investigated with hysteroscopy. J Obstet Gynaecol 2001;21(4):39295.

5. Lidor A, Ismajovich $\mathrm{B}$, Confino E, David MP. Histopathological findings in 226 women with postmenopausal uterine bleeding. Acta obstetricia et Gynecol Scandinav. 1986 ;65(1):41-3.

6. Gredmark T, Kvint S, Havel G, Mattsson LÅ. Histopathological findings in women with postmenopausal bleeding. BJOG: Int $\mathrm{J}$ Obstet Gynaecol. 1995;102(2):133-6.

7. Agrawal L, Fusey S: Role of vaginal scan in measurement of endometrial thickness in women with postmenopausal bleeding. Thesis for (M.D. Obst. Gynaecol ), Nagpur university, Nagpur, 1997.

8. Dørum A, Kristensen GB, Langebrekke A, Sørnes T, Skaar O. Evaluation of endometrial thickness measured by endovaginal ultrasound in women with postmenopausal bleeding. Acta obstetricia et Gynecol Scandinav. 1993;72(2):116-9.

9. Ind T. Management of postmenopausal bleeding Prog Obstet Gynaecol. 1998:13;361.

10. Haller H, Matejčić N, Rukavina B, Krašević M, Rupčić S, Mozetič D. Transvaginal sonography and hysteroscopy in women with postmenopausal bleeding. Int J Gynecol Obstet. 1996;54(2):155-9.

11. Reddi Rani P, Devi JK, Papa D, Jayanthis. Transvaginal sonography and progesterone challenge test for identifying endometrial pathology in postmenopausal women J Obstet Gynecol India.2002;52(1):135-8.

12. Nasri MN, JH Shephard, Setchall ME, Lowe DG, Chard $\mathrm{T}$. The role of vaginal scan in measurement of endometrial thicknes sin postmenopausal women Brit $\mathbf{J}$ Obstet Gynaecol. 1991:98(5);470-5.

13. Karlsson B, Granberg S, Wikland M, Ylöstalo P, Torvid $\mathrm{K}$, Marsal K et al. Transvaginal ultrasonography of the endometrium in women ith postmenopausal bleeding A nordiac multicentric study Am J Obstet Gynaecol 1995;172(5):1488-94.

14. Brewer JI, Miller WH. Postmenopausal uterine bleeding. Am J Obstet Gynecol. 1954;67(5):988-1013.

Cite this article as: Agrawal M, Kotpalliwar MK, Kotpalliwar S. Clinicopathological evaluation of postmenopausal bleeding. Int J Reprod Contracept Obstet Gynecol 2018;7:5076-83. 